\title{
Long-term health consequences of poor nutrition during pregnancy
}

\author{
Germaine Miese-Looy, Jessica Rollings-Scattergood, and Anna Yeung
}

This review reflects equal contributions from the three authors. The work was initiated as a group research project for BIOM*4010 Teratology under the supervision of Prof. Neil MacLusky.

\begin{abstract}
The long-term effects of poor prenatal nutrition are becoming a matter of increasing concern throughout the world. While the consequences of inadequate caloric and/or vitamin intake during pregnancy have been well characterized, in recent years it has become clear that serious long-term adverse effects may also result from gestational nutrient imbalance, even when total caloric intake is more than sufficient to meet the demands of pregnancy. Excessive fat, carbohydrate or protein intake may permanently alter the homeostatic mechanisms in the fetus, predisposing the offspring of affected pregnancies to serious chronic diseases, including cardiovascular disease, diabetes and cancer. This review summarizes the growing literature on this subject, with particular emphasis on the lasting health-related effects of macronutrient imbalance on fetal development.
\end{abstract}

$\mathrm{N}_{\mathrm{u}}^{\mathrm{u}}$ utrition has a critical role in overall health status. Both under- and over-nutrition may seriously impact on long term health status and life expectancy. Well publicized studies over the last 50 years have clearly demonstrated links between obesity and many of the most serious chronic human diseases, including diabetes, cardiovascular disease and cancer ${ }^{1}$.

What is less well-known is the fact that prenatal malnutrition can have lasting effects on the children from affected pregnancies. Most of the research to date has focused on micronutrients, such as vitamins and minerals, which have been widely recognized to play a critical role in fetal health outcome ${ }^{2,3}$. A less well-defined, but equally important, area of study is the influence of the macronutrient status in the mother. Carbohydrates, lipids and proteins are necessary for energy requirements and need to be maintained in a proper balance for optimal health and growth. During pregnancy, maternal energy requirements are substantially increased, exacerbating the consequences of an unhealthy or inadequate diet in the mother.

While the idea that inadequate macronutrient status during pregnancy might impair fetal development seems almost self-evident given the metabolic demands of pregnancy, there is a growing body of evidence to indicate that excessive macronutrient intake can also have serious long-term heath consequences. Currently, the North American diet tends toward excessive fat and carbohydrates, resulting in macronutrient overindulgence. The incidence of diseases associated with overeating is on the rise ${ }^{4,5}$. The direct effects can be seen in the current generation; negative consequences on the offspring of these individuals are only now becoming apparent. In other regions of the world the opposite situation exists, in which people are unable to obtain adequate nutrition, particularly protein. Surprisingly, the effects of inadequate nutrition frequently mirror the effects of overeating, suggesting potential common underlying mechanisms of response to abnormal dietary conditions.

The goal of this article is to summarize the available information on the long-term health consequences of inadequate prenatal nutrition and to link this information to potential underlying mechanisms in pregnancy. The mechanisms involved in fetal metabolic programming will be briefly described, leading into consideration of the consequences of abnormal macronutrient intake on specific organ systems. Finally, we consider the potential long-term public health impact of inadequate prenatal nutritional care, within the context of ongoing efforts to improve maternal nutritional status.

\section{The Concept of "Fetal Programming"}

The first evidence for long-term effects of malnutrition in pregnancy came from studies performed on human populations exposed to famine. A particularly well-studied epidemiological example is the Dutch Hunger Winter. From 1944 to 1945 , residents in the Netherlands were subjected to a period of food rationing, where caloric intake fell as low as 
400-800 calories per day (typical caloric intake is approximately 2000 calories per day ${ }^{6}$.) Follow-up studies done on people born during that time found that the affected individuals had impaired glucose tolerance, a greater incidence of coronary heart disease and elevated blood pressure ${ }^{6}$. The potential links between overall nutritional status and long term health have been expanded over the years. Essentially, malnutrition in utero is viewed as causing the fetus to undergo to structural and functional changes that result in an increased risk for disease and physiological impairment in adulthood ${ }^{7}$. How this occurs remains the subject of considerable debate, but a number of clues have emerged from studies in experimental animals. In rodents, insufficient levels of protein are associated with an increase in age-related disorders and thereby a decrease in lifespan ${ }^{8}$. At birth, many of these animals are born smaller than their control counterparts but postnatally they exhibit a period of catch-up growth that has a faster rate of weight gain than the controls 9 . This predisposes the offspring to overeating, causing obesity that presages subsequent disorders ${ }^{10}$. The fetus, in effect, is programmed to adapt to the kind of diet that it "expects" after birth, adapting metabolic and hormonal regulatory processes to be compatible with that particular diet 11. This results in a constellation of disorders (collectively termed the "metabolic syndrome") when the postnatal diet exceeds energy requirements. Consequences of disrupting metabolic processes during development include cardiovascular dysfunction, hypertension and obesity ${ }^{11}$, as well as effects on the urogenital ${ }^{12}$ and central nervous systems ${ }^{13}$. Because of the links between hormonal and nutritional status and long-term cancer risk, prenatal dietary abnormalities may cascade into increased cancer incidence. The long-term consequences of fetal malnutrition also appear to be system-dependent: some systems can overcome prenatal nutritional stress, while others appear to be irreversibly programmed ${ }^{14}$. It is not yet known what mechanisms are responsible for the programming of some functions, leaving others to remain malleable after birth ${ }^{14}$.

One other important consideration in evaluating the effects of prenatal nutrition is that the effects may be highly dependent on when during the pregnancy the metabolic problem occurred. The concept that there are "critical" periods during development in which an abnormal nutrition may have particularly severe effects echoes observations in endocrinology that have shown that the effects of hormone imbalance are likewise highly dependent on the stage of development at which the imbalance occurred ${ }^{15}$. As we will see, this may be more than coincidental because many of the lasting effects of prenatal malnutrition may at least partially be based on alterations in endocrine homeostasis. The potential hormonal link is emphasized by studies indicating that long-term effects of prenatal malnutrition may be highly sex dependent. Abnormal protein intake in rat pregnancy, for example, affects blood pressure, food efficiency and body weight of the offspring in adulthood in a sex-dependent manner ${ }^{16-18}$.

\section{MACRONUTRIENT Transfer to THE FetUS: THE Role OF THe Placenta}

In order for the fetus to maintain adequate growth and development, nutrients must reach the uterine environment, commencing before implantation of the embryo. During the first trimester, the placenta has not yet established a strong connection between fetal and maternal circulations, so nutrients are provided by the endometrium and placenta ${ }^{19}$. Once the placenta has been established, it acts as the link between the mother and the fetus. The basic structure of the human placenta at birth consists of maternal capillaries, the intervillous space, microvillous membrane (MVM), the syncytiotrophoblast, the basal membrane (BM), the cytotrophoblast, and fetal capillaries ${ }^{19}$. The placenta acts as a barrier through which passage of macronutrients is highly regulated, primarily by specific transporter proteins. There are many similarities in the transport of the three major macronutrients, each of which affect the fetal environment accordingly.

Glucose has been one of the most studied macronutrients in relation to fetal development because it is the primary energy source for the fetus. There are six main transporters for glucose (GLUT1 - GLUT6; ${ }^{19}$. GLUT1 is the major transporter in the placenta and exists on both the MVM and BM. There is significantly higher expression of GLUT1 on the MVM than on the BM, and it has been widely accepted that the BM acts as the rate-limiting step for glucose transfer from mother to fetus ${ }^{20-22}$. GLUT1 transporter proteins demonstrate saturation kinetics, which assist in the regulation of glucose transfer. ${ }^{23}$ However, the fetus can obtain glucose from both maternal circulation and the placenta via breakdown of glycogen precursors 23,24 . Thus, both the amount of GLUT1 and the placental concentration of glucose regulate the amount of glucose actually reaching the fetus. Placental glycogen concentrations are highest in early gestation and decrease until term ${ }^{24}$. Similarly, the concentration of GLUT1 transporters in the placenta decreases over gestation. This could be due to both the immaturity of the placental link during early gestation, as well as increased fetal glucose production towards the end of gestation. Although the overall number of transporters increases to provide for the growing energy needs of the fetus, their absolute concentration declines due to the increased size of the placenta ${ }^{23}$. Hence, while the fetus is most dependent on the mother for glucose in early gestation, if the mother experiences hyperglycemia, the fetus will be exposed to this increase in blood glucose concentration throughout gestation.

Amino acid (AA) concentrations are higher in the fetus compared to the mother, an indication of their vital role in 
fetal development 22,23 . AAs are utilized as sources for carbon and nitrogen, inter-conversion to other amino acids, as well sources of metabolic energy for the placenta or fetus 25. While the placenta itself metabolizes and utilizes amino acids ${ }^{26}$, there are three fundamental steps of AA transfer across a placenta into the fetus: uptake from the maternal circulation across the MVM, transport through the trophoblast cytoplasm, and transport out of the trophoblast across the BM into fetal circulation ${ }^{25}$. Most AA transport is energy-dependent, the AA being taken into the placenta by transporters, concentrated and then released into the fetal circulation ${ }^{23}$. Although AA transporters are highly stereospecific in that L-amino acids are transported more easily than D-amino acids, they also have overlapping specificity, allowing several different AAs to be transported simultaneously ${ }^{26}$. System A is the most researched and wellunderstood AA transporter. It is a sodium-dependent, neutral

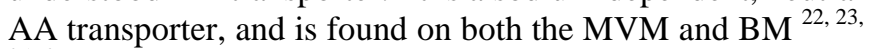
25, 26. Some AAs are not transported from the mother at all, including the anionic AAs, glutamate and aspartate ${ }^{23,25}$. These AAs must be produced in the fetal liver or in the placenta itself. Branched-chain AAs are also not simply taken up by the placenta from maternal circulation and then released to the fetus. They are partially metabolized into their ketoacids when they enter the placenta from maternal circulation, and assist in providing nitrogen for further AA and protein synthesis at the fetal liver ${ }^{23,25}$. Both of these mechanisms demonstrate the cooperative relationship between the fetal liver and placenta in regulating AA concentration and exposure to the fetus.

Relatively little is known about the transfer of lipids to the fetal environment. Not surprisingly, fetal access to lipids is regulated and determined by the maternal diet as well as placental lipid transport ${ }^{23}$. The first crucial step of lipid transfer involves the action of lipoprotein lipase (LPL) on the MVM ${ }^{22}$. The growing fetus is particularly reliant on arachidonic acid (omega-6) and docosahexaenoic acid (omega-3) provided by the mother ${ }^{27}$. Maternal intake of both omega- 3 and omega- 6 fatty acids has been shown to have an effect on membrane composition ${ }^{28}$. It has also been shown that consumption of high fat diets has deleterious health effects on the fetus ${ }^{27}$, suggesting some alteration or insufficient regulation of placental transport. With respect to metabolism of fatty acids within the placenta, it appears that medium-chain fatty acids are preferentially provided to the fetus, as a result of chain altering metabolism within the placenta ${ }^{23}$. The final step involves ketones, which have been shown to cross the placenta into fetal circulation, and then are readily taken up by fetal tissues for oxidative metabolism. In addition to these specific macronutrient systems, it is important to note that a number of hormonal control systems are affected by nutritional status, potentially leading to lasting effects on the "set-points" of internal homeostatic systems that will extend into postnatal life. The most significant long-term alterations occur in the hypothalamicpituitary-gonadal axis ${ }^{29}$. Insulin levels are severely affected by a high carbohydrate diet, which may predispose to hyperinsulinism in later life ${ }^{30}$. Effects on glucocorticoid levels have also been documented, which have been hypothesized to correlate to an increased set-point in the hypothalamic-pituitary-adrenal (HPA) axis ${ }^{31}$. The fetus has mechanisms to protect itself against these excesses, but if hormone levels rise sufficiently high they may become saturated and fail. One of the key mediators of glucocorticoid transfer across the placenta is the enzyme $11 \beta$-hydroxysteroid dehydrogenase type-2 (11 $\beta$-HSD2) which converts the potent glucocorticoid cortisol into the much less biologically active cortisone ${ }^{32}$. In the offspring of dams fed low protein diets, placental levels of activity and mRNA expression of the $11 \beta$-HSD2 are reduced ${ }^{33}$. $11 \beta$ HSD2 acts as a "gatekeeper", limiting the amount of glucocorticoids that can cross the placenta ${ }^{32}$. Exposure of the fetus to excessive levels of glucocorticoids increases later susceptibility to inappropriate stress responses, hypertension and renal injury ${ }^{34,35}$.

Another regulatory mechanism that is altered is sensitivity to leptin, one of the key regulatory hormones associated with appetite. When there are increased levels of leptin, an individual feels satiated ${ }^{36}$. Rats exposed to low protein in utero and then allowed to self select food postnatally became hyperphagic with elevated plasma concentrations of leptin and an increased fat pad mass, suggesting that they have become resistant to normal satiety signals ${ }^{36}$. Likewise, increased insulin resistance could also explain the obesity often seen in protein deficient offspring. Similar to leptin, elevated insulin levels suppress appetite through their effects on hypothalamic satiety centers ${ }^{36}$. However, with reduced insulin sensitivity, this normal satiety response may be lost. Consistent with this hypothesis, selective elimination of insulin receptors in the brain has been demonstrated in mice to result in loss of normal appetite control and obesity ${ }^{37}$.

\section{EFFECTS OF MACRONUTRIENT IMBALANCE ON SPECIFIC ORgAN SYSTEMS}

\section{Congenital Malformations and Birth Weight}

Poor glycaemic control in diabetic mothers is associated with numerous serious effects, including a three-fold increase in congenital malformations as well as increases in miscarriage rates and perinatal mortality, compared to those with optimal glycaemic control ${ }^{38}$. The associated high glucose levels seen in these individuals also put them at an elevated risk for greater fetal and placental growth, leading to an increased risk for cesarean section deliveries ${ }^{39-41}$. As well, there is an elevated risk for pre-eclampsia, a condition that puts both the mother and child at risk ${ }^{42}$. At the other end of the spectrum, a low carbohydrate intake in pregnancy has a restrictive 
effect on fetal growth, indicating that maintenance of glucose levels within the normal range is important for optimal pregnancy outcome ${ }^{43}$.

One of the goals of the metabolic adaptations to fetal malnutrition appears to be to spare the brain from the effects of an inadequate nutrient supply as much as possible. Nevertheless, effects of prenatal malnutrition on brain development are still observed ${ }^{13}$. As the body attempts to adapt to reduced caloric intake by reducing rates of metabolism, it is hypothesized that decreased cerebral metabolism is maintained after birth ${ }^{13}$. Epidemiological studies have shown neurological, emotional and cognitive effects of prenatal malnutrition ${ }^{13}$. A decrease in dendritic numbers was noted in malnourished offspring ${ }^{44}$. This decline could be associated with a decreased blood flow due to reduced nutrient supply ${ }^{13}$. A diet unbalanced in fatty acids can affect the fetal transfer of essential fatty acids. For example, improper fat intake has been reported to have adverse cerebral effects, with decreased docosahexaenoic acid levels due to reduced fetal transfer ${ }^{45}$.

Congenital abnormalities are seen with increased frequency in fetuses exposed to high glucose levels throughout birth ${ }^{46}$. These outcomes include an increased risk for renal agenesis, obstructive abnormalities of the urinary tract, cardiovascular and multiple congenital abnormalities ${ }^{46}$. Specifically, a 200-fold increase is seen in the incidence of caudal regression in diabetic mothers. While it is a relatively rare condition in healthy mothers, it affects 1 in 350 diabetic births ${ }^{47}$. It is difficult to separate the diabetic effects from the effects of hyperglycemia ${ }^{46}$ since the two conditions usually occur concurrently.

\section{Liver}

The liver is one of the most important organs involved in glucose homeostasis, being sensitive to the effects of both insulin and glucocorticoids. It is therefore not surprising that fetal malnutrition has lasting effects on the liver. In rats exposed in utero to a low protein diet, there are fewer but larger liver lobules ${ }^{48}$. In adulthood, the response of these livers to glucagon or glucagon plus insulin infusion is altered, glucose output consequent to glucagon stimulation being reduced while addition of insulin resulted in an anomalous initial increase in glucose output followed later by the expected reduction. These changes were associated with both a reduction in glucagon receptors and an increase in insulin receptors in the liver ${ }^{9}$.

\section{Urogenital System}

Effects of an unbalanced diet on the urogenital system include increased risks of hypertension and renal dysfunction. A low protein diet predisposes offspring to problems with renal structure and function ${ }^{49}$. Overall, kidney weight in proportion to body weight is smaller ${ }^{50}$, the development of the kidney is impeded and progression to renal failure occurs much sooner than normal ${ }^{7,51}$.
Low protein and high glucose studies have demonstrated that the offspring of altered nutritional status dams have fewer renal glomeruli 49,51 . As a result, the glomeruli undergo compensatory postnatal hypertrophy ${ }^{51}$. In turn, this increases the average glomerular volume and elevates protein levels, such as albumin and creatinine, excreted in the urine 49. Individuals with proteinuria often have kidney disease ${ }^{49}$, as this indicates a decreased permeability of the glomerular membranes ${ }^{50}$. Eventually, this pathway results in renal disorders, particularly hypertension ${ }^{51}$.

Part of the mechanism for this effect is probably upregulation of the renin-angiotensin pathway. Studies have observed that low protein diet in pregnancy results in an increased vascular reaction when Angiotensin II (AngII) is administered ${ }^{52}$. Administration of drugs that work to reduce hypertension (e.g. captopril, an angiotensin converting enzyme inhibitor) will counteract this effect in early postnatal life ${ }^{52}$. The offspring of pregnant rats fed a high fat diet exhibit decreased renin and the $\mathrm{Na}+\mathrm{K}+$-ATPase activity but other than that, it does not appear that a high fat diet has a significant effect on renal function ${ }^{53}$. By contrast, a maternal low protein diet induces hypertension in the offspring and is associated with a higher level of reactive oxygen species and an increased immune cell infiltration into the kidney ${ }^{54}$, indicating a greater potential for renal damage. Sexual maturation is also affected by prenatal nutritional status. In general, decreased nutrition dampens the ability of fetus to produce gonadotrophins, resulting in a delayed sexual maturation ${ }^{12}$. The consequences of reduced fetal gonadotrophin output appear to be particularly severe in males, at least in part because of the dependence of the male on testicular androgen production, for normal sexual differentiation of both the reproductive organs and the brain and pituitary systems responsible for reproductive control. In protein deficient male offspring, one study found higher levels of glucocorticoids in the dams, as well as an increase in ano-genital distance and a delay in testicular descent, markers of sexual differentiation ${ }^{12}$. Male rats exposed to any stress in utero have less sexual activity ${ }^{55}$.

\section{Cardiovascular System}

The heart and major blood vessels are one of the first organ systems to develop. These begin functioning during the first trimester in humans, and continue to develop into late gestation. Since development of the heart and vasculature begins early and continue for the remainder of pregnancy, it is not surprising that significant effects are seen in response to maternal diet.

Relatively few studies have focused specifically on prenatal abnormalities in glucose regulation and their potential long term cardiovascular sequelae, but what has been done suggests that glucose regulation is critical for normal cardiac development. It is known that a high blood glucose concentration in the mother is transferred to the fetus 56 . It has also been determined that high concentrations of 
Table 1: Effects of high prenatal lipid intake on offspring.

\begin{tabular}{|l|l|l|}
\hline Observations in offspring & Implications & References \\
\hline $\begin{array}{l}\text { - increased blood pressure in } \\
\text { females } \\
\text { - abnormal plasma lipids and } \\
\text { triglycerides }\end{array}$ & $\begin{array}{l}\text { - leads to hypertension and other } \\
\text { vascular abnormalities }\end{array}$ & $11,60,61$ \\
\hline $\begin{array}{l}\text { - fatty acid abnormalities in } \\
\text { aortic tissue composition } \\
\text { - vascular fatty acid profile } \\
\text { pronounced in females in } \\
\text { adulthood }\end{array}$ & - decreased functionality & 60,61 \\
\hline $\begin{array}{l}\text { - decreased relaxation by } \\
\text { acetylcholine }\end{array}$ & - increased vascular dysfunction \\
\hline $\begin{array}{l}\text { - decreased maximum relaxation } \\
\text { of arteries }\end{array}$ & 62 \\
\hline
\end{tabular}

fetal blood glucose lead to the premature fetal secretion of insulin ${ }^{22}$. A large study on the outcomes of 4180 pregnancies complicated by gestational or type II diabetes found that initial fasting serum glucose and glycosylated hemoglobin levels were significantly higher in pregnancies with major congenital abnormalities. Cardiac malformations accounted for $37.6 \%$ of these major abnormalities ${ }^{57}$.

Low maternal protein and high maternal fat intake diets have both been demonstrated to have serious effects on the cardiovascular system. In offspring of female rats who consumed a low protein diet, increased apoptosis of the cardiac myocytes has been observed during the fetal period, leading to hypertrophy ${ }^{58}$. In particular, the left ventricles were found to initially have a thin muscular wall, which then thickened past the point of normalcy. This increased rate of cell division predisposes the myocytes, and therefore the heart, to dysfunction or disease later in life ${ }^{58}$.

Since lipids are the main structural component of cell membranes, it is not surprising that maternal fatty acid status appears to affect fetal development of the cardiovascular system. Most studies to date have been done using the rat model. A low arachidonic acid diet has been found to have a profound influence on cardiovascular development in utero: in both rats and humans exposure to a low arachidonic acid diet in pregnancy reduces birth weight, increases resting heart rate and reduces the number of insulin receptors on heart muscle, which can lead to increased cardiac muscle insulin resistance later in life ${ }^{59}$. A high fat maternal diet also appears to predispose the fetus to cardiovascular dysfunction. It is known that endothelial dysfunction causes an increased risk in cardiovascular disease, and any developmental irregularities in early gestation will lead to endothelial dysfunction of the vasculature ${ }^{60}$.

In general, increased lipid consumption during pregnancy leads to decreased ability of the vasculature to adapt to pressure changes, which adds to the already impaired functionality of the heart and blood vessels. In humans, an elevated level of fatty atherosclerotic streaks has been observed in the fetus when the maternal diet was high in saturated fats ${ }^{62}$.

\section{The Mammary Gland: Breast Cancer Incidence}

The prevalence of breast cancer is steadily increasing in countries with high dietary fat consumption. In comparison, countries with low fat intake such as those in East Asia demonstrate a far lower level of breast cancer occurrence ${ }^{10}$. While there is a substantial genetic component in breast cancer, genetics are not the regulating factor behind this higher incidence in Western over East Asian countries, as shown by the increase in breast cancer rates among Asian immigrants to the West ${ }^{10}$. There has been intense research into the correlation between a high fat diet and breast cancer incidence. Investigations have focused on the role of maternal diet to determine if any correlations can be detected, in order to determine the origins of breast cancer.

It has previously been observed that a high estrogenic environment in utero, such as in the case of dizygotic female twins, increases the risk of breast cancer in female offspring 63. It has been hypothesized that the greater occurrence of breast cancer in offspring of mothers ingesting a high fat diet may be due to increased aromatization in fat tissue, as well as activation of $\mathrm{P} 450$ aromatase by fatty acids resulting in a higher rate of conversion of androstenedione to estrone ${ }^{10}$. A 1997 study conducted by Hilakivi-Clarke et al has shown that in comparison to low-fat offspring, prenatal exposure to a diet high in n-6 PUFA (polyunsaturated fatty acids) causes an increase in the levels of circulating estrogens by $30 \%$, associated with an increased risk of breast cancer in the offspring ${ }^{64}$. No increase in breast cancer was noted if the levels of estrogen were not raised, giving further support to the role of estrogen in the initiation of breast cancer ${ }^{10}$. As there is no change in the offspring's production of estrogen postnatally, the influence of the estrogen must have effect during the in utero period. It also appears that changes are 
restricted to exposure occurring during the initial rapid growth period ${ }^{64}$, thereby indicating a critical period when exposure can affect neoplastic occurrence.

A high estrogenic in utero environment is also associated with alterations to mammary gland development ${ }^{10}$. In offspring of rats fed a high-fat diet, the mammary fat pad was larger, epithelial cell density was greater and there were more terminal end buds (TEB's) ${ }^{63}$. These changes in mammary morphology of rats are theorized to play a role in the increased incidence of breast cancer. TEB's are the sites of carcinogen-induced malignant transformation, therefore, any increase in the number of these structures potentially increases the number of sites from which carcinoma could arise ${ }^{63,64}$. This correlates with the location of malignant alteration in the human, the terminal ductal-lobular units, which arise directly from TEB's. An increase in locations for neoplastic transformations suggests that the greater incidence of breast cancer in high fat-exposed offspring may at least partially arise through alterations in mammary structure.

Mammary structure alone may not, however, completely explain the observed increases in breast cancer incidence. In one study, the onset of puberty was advanced in the offspring of mothers fed the high-fat diet ${ }^{63}$. An association between early puberty and breast cancer risk has previously been identified in humans ${ }^{65}$. Precocious sexual maturation may further enhance the susceptibility of those exposed to high levels of prenatal estrogen.

Different pathways have been proposed as possible links between a high n-6 PUFA diet resulting in n-3 deficiency and increased breast cancer risk. These pathways, while not fully investigated, are important to consider. For one, prostaglandins, products of arachidonic acid metabolism, are lower in those who consume increased levels of n-3 PUFA 66. While it seems biologically plausible that the protective mechanisms of n-3 PUFA work through a decrease in prostaglandin, no increase in prostaglandin levels has yet to be documented as a correlation with tumour growth ${ }^{10}$. Another suggested pathway is the decrease of the compounds 12-hydroxyeicosatetraenoic (12-HETE) and 15hydroxeicosatetraenoic (15-HETE) in the mammary tumour tissue of those fed increased levels of n-3 PUFA ${ }^{66}$. It has also been proposed that a change in lipid peroxidation activity resulting from the addition of n-3 PUFA may provide additional protection ${ }^{63}$. Cells that exhibit increased lipid peroxidation are more likely to undergo apoptosis and therefore have less probability of malignant transformation 63 .

\section{SUMMARY AND CONCLUSIONS}

The value of prenatal nutritional intervention as a means of improving long term population health has been amply demonstrated by experience with micronutrients. In the 1990s, for example, it was established that the incidence of neural tube defects in pregnancy could be dramatically reduced by supplementation of the diet with folic acid ${ }^{3}$. Since 1998, when the US Government instituted folate supplementation of grain products, the incidence of neural tube defects in the US population has substantially declined 67

It now seems likely that even greater long-term health advantages could result from preventing macronutrient imbalance in pregnancy. All three macronutrient imbalances discussed here have detrimental outcomes that could be prevented with proper care and education. Unfortunately, current education programs are criticized for not offering enough information for the most at risk groups, specifically those with gestational diabetes ${ }^{68}$. For example, education centers helped to prevent abortion risk, but women were still at increased risk for severe malformations due to improper glycaemic control ${ }^{68}$. Many of the drugs available for the treatment of diabetes, other than insulin, are however still under review to investigate their potentially teratogenic effects, which limits the potential for therapeutic intervention 69.

Increased fat intake in the Western world is a great concern for the entire population, but especially for women of child-bearing age. The high-fat diets in the rat studies that have demonstrated adverse pregnancy outcome are representative of the fat intake of Caucasian women in Westernized countries. There is a great need for further education, not only on the amount of fat consumed, but also the type of fat. In most Western countries, the diet is high in arachidonic acid and deficient in docosahexaenoic acid ${ }^{10}$. Saturated fats need to be limited in the diet for many reasons, not the least of which is the disruption of the fetal transfer of essential fatty acids ${ }^{27}$.

Protein deficiency in the developing world will always be a concern but greater understanding of its consequences may improve long term health outcomes. Insufficient levels of protein directly affect the number of enzymes available for lipid metabolism ${ }^{45}$. Similarly, altering the levels of nutrients available appears to affect levels of potential methyl donors, thereby affecting the expression of certain genes ${ }^{70}$ via epigenetic mechanisms ${ }^{71}$. Modifiers of gene expression such as DNA methylation or histone acetylation essentially turn genes off so proteins are not produced ${ }^{72}$. It has been suggested that supplementation of low protein diets with methionine, to provide methyl groups ${ }^{73}$, could ameliorate some of the long term adverse consequences, but whether or not this is an effective practice is still unclear ${ }^{71}$.

Through these educational and prenatal programs, care must be taken to address cultural and ethnic differences between the groups to ensure that any cultural food requirements are properly addressed. Differences have also been found between food purchasing behaviour and socioeconomic class, with those in the lower end more likely 
to purchase less nutritionally dense foods, indicating a target group where increased focus must be placed on changing food buying habits ${ }^{74}$.

More research is needed to determine the mechanisms of macronutrient pathology. However, this should not prevent the implementation of programs to help expecting mothers provide for their growing fetus. In light of all the evidence presented, it appears that the best recourse is patient education and providing access to premium prenatal programs ${ }^{68}$. This is required to protect the health of not only the offspring, but also of the mother. It has been stated repeatedly in the scientific literature that the prevention is the best defense. By providing the mother with information and therapy to avoid many of the pathologies noted, the offspring is given the optimal chance at survival.

\section{Correspondence}

The corresponding author is Germaine Miese-Looy, Department of Biomedical Sciences, University of Guelph gmieselo@uoguelph.ca. Germaine Miese-Looy is with Analytical Laboratory Services, University of Guelph, Jessica Rollings-Scattergood is with the McMaster University Medical School, and Anna Yeung is with the University of Melbourne, Melbourne, Australia.

\section{REFERENCES}

1. Taubert KA, Clark NG, Smith RA 2007 Patient-centered prevention strategies for cardiovascular disease, cancer and diabetes. Nat Clin Pract Cardiovasc Med 4:656-66

2. Pathak P, Kapil U 2004 Role of trace elements zinc, copper and magnesium during pregnancy and its outcome. Indian J Pediatr 71:1003-5

3. Djukic A 2007 Folate-responsive neurologic diseases. Pediatr Neurol 37:387-97

4. Bray GA, Bellanger T 2006 Epidemiology, trends, and morbidities of obesity and the metabolic syndrome. Endocrine 29:109-17

5. Romero-Corral A, Montori VM, Somers VK, et al. 2006 Association of bodyweight with total mortality and with cardiovascular events in coronary artery disease: a systematic review of cohort studies. Lancet 368:666-78

6. Painter RC, Roseboom TJ, Bleker OP 2005 Prenatal exposure to the Dutch famine and disease in later life: an overview. Reprod Toxicol 20:345-52

7. Langley-Evans SC 2006 Developmental programming of health and disease. Proc Nutr Soc 65:97-105

8. Sayer 2001 Prenatal exposure to a maternal low protein diet shortens life span in rats Gerontology. Karger., Basel, , p 9

9. Ozanne SE, Hales CN 2004 Lifespan: catch-up growth and obesity in male mice. Nature 427:411-2

10. Hilakivi-Clarke L, Clarke R, Lippman M 1999 The influence of maternal diet on breast cancer risk among female offspring. Nutrition 15:392-401
11. McArdle HJ, Andersen HS, Jones H, Gambling L 2006 Fetal Programming: Causes and Consequences as Revealed by Studies of Dietary Manipulation in Rats \&ndash; A Review. Placenta 27:56-60

12. Zambrano E, Rodriguez-Gonzalez GL, Guzman C, et al. 2005 A maternal low protein diet during pregnancy and lactation in the rat impairs male reproductive development. J Physiol 563:275-84

13. Gallagher EAL, Newman JP, Green LR, Hanson MA 2005 The effect of low protein diet in pregnancy on the development of brain metabolism in rat offspring. The Journal of Physiology 568:553-558

14. Calder 2000 The level of protein and type of fat in the diet of pregnant rats both affect lymphocyte function in the offspring Nutrition research. Pergamon Press, New York, p 995

15. Plagemann A, Harder T, Rake A, Melchior K, Rohde W, Dorner G 2000 Hypothalamic nuclei are malformed in weanling offspring of low protein malnourished rat dams. J Nutr 130:2582-9

16. Thone-Reineke C, Kalk P, Dorn M, et al. 2006 Highprotein nutrition during pregnancy and lactation programs blood pressure, food efficiency, and body weight of the offspring in a sex-dependent manner. AJP - Regulatory, Integrative and Comparative Physiology 291:R1025-1030

17. Zambrano E, Martinez-Samayoa PM, Bautista CJ, et al. 2005 Sex differences in transgenerational alterations of growth and metabolism in progeny (F2) of female offspring (F1) of rats fed a low protein diet during pregnancy and lactation. J Physiol 566:225-36

18. McMullen S, Langley-Evans SC 2005 Maternal lowprotein diet in rat pregnancy programs blood pressure through sex-specific mechanisms. Am J Physiol Regul Integr Comp Physiol 288:R85-90

19. Illsley NP 2000 Glucose transporters in the human placenta. Placenta 21:14-22

20. Jansson T, Wennergren M, Powell TL 1999 Placental glucose transport and GLUT 1 expression in insulindependent diabetes. American Journal of Obstetrics and Gynecology 180:163-168

21. Jansson T, Ekstrand Y, Wennergren M, Powell TL 2001 Placental glucose transport in gestational diabetes mellitus. Am J Obstet Gynecol 184:111-6

22. Jansson T, Powell TL 2006 IFPA 2005 Award in Placentology Lecture. Human placental transport in altered fetal growth: does the placenta function as a nutrient sensor? -- a review. Placenta 27 Suppl A:S91-7

23. Hay WW, Jr. 1995 Metabolic interrelationships of placenta and fetus. Placenta 16:19-30

24. Leonce J, Brockton N, Robinson S, et al. 2006 Glucose production in the human placenta. Placenta 27 Suppl A:S103-8

25. Battaglia FC, Regnault TR 2001 Placental transport and metabolism of amino acids. Placenta 22:145-61 
26. Cetin I 2003 Placental transport of amino acids in normal and growth-restricted pregnancies. Eur J Obstet Gynecol Reprod Biol 110 Suppl 1:S50-4

27. Ghebremeskel K, Bitsanis D, Koukkou E, Lowy C, Poston L, Crawford MA 1999 Maternal diet high in fat reduces docosahexaenoic acid in liver lipids of newborn and sucking rat pups. Br J Nutr 81:395-404

28. Friesen R, Innis SM 2006 Maternal dietary fat alters amniotic fluid and fetal intestinal membrane essential n6 and n-3 fatty acids in the rat. AJP - Gastrointestinal and Liver Physiology 290:G505-510

29. James WP 1997 Long-term fetal programming of body composition and longevity. Nutr Rev 55:S31-41; discussion S41-3

30. Plagemann A 2004 'Fetal programming' and 'functional teratogenesis': on epigenetic mechanisms and prevention of perinatally acquired lasting health risks. J Perinat Med 32:297-305

31. Khan AS, Sane DC, Wannenburg T, Sonntag WE 2002 Growth hormone, insulin-like growth factor-1 and the aging cardiovascular system. Cardiovasc Res 54:25-35

32. Sampath-Kumar R, Matthews SG, Yang K 1998 11betaHydroxysteroid Dehydrogenase Type 2 Is the Predominant Isozyme in the Guinea Pig Placenta: Decreases in Messenger Ribonucleic Acid and Activity at Term. Biology of Reproduction 59:1378-1384

33. Bertram C, Trowern AR, Copin N, Jackson AA, Whorwood CB 2001 The maternal diet during pregnancy programs altered expression of the glucocorticoid receptor and type 2 11betahydroxysteroid dehydrogenase: potential molecular mechanisms underlying the programming of hypertension in utero. Endocrinology 142:2841-53

34. Dodic M, Abouantoun T, O'Connor A, Wintour EM, Moritz KM 2002 Programming effects of short prenatal exposure to dexamethasone in sheep. Hypertension 40:729-34

35. Banjanin S, Kapoor A, Matthews SG 2004 Prenatal glucocorticoid exposure alters hypothalamic-pituitaryadrenal function and blood pressure in mature male guinea pigs. J Physiol 558:305-18

36. Vickers $\mathrm{MH}$, Breier BH, Cutfield WS, Hofman PL, Gluckman PD 2000 Fetal origins of hyperphagia, obesity, and hypertension and postnatal amplification by hypercaloric nutrition. Am J Physiol Endocrinol Metab 279:E83-7

37. Bruning JC, Gautam D, Burks DJ, et al. 2000 Role of brain insulin receptor in control of body weight and reproduction. Science 289:2122-5

38. Inkster ME, Fahey TP, Donnan PT, Leese GP, Mires GJ, Murphy DJ 2006 Poor glycated haemoglobin control and adverse pregnancy outcomes in type 1 and type 2 diabetes mellitus: systematic review of observational studies. BMC Pregnancy Childbirth 6:30
39. Scholl TO, Chen X, Khoo CS, Lenders C 2004 The dietary glycemic index during pregnancy: influence on infant birth weight, fetal growth, and biomarkers of carbohydrate metabolism. Am J Epidemiol 159:467-74

40. King JC 2006 Maternal obesity, metabolism, and pregnancy outcomes. Annu Rev Nutr 26:271-91

41. Allen VM, Armson BA, Wilson RD, et al. 2007 Teratogenicity associated with pre-existing and gestational diabetes. J Obstet Gynaecol Can 29:927-44

42. Nordin NM, Wei JW, Naing NN, Symonds EM 2006 Comparison of maternal-fetal outcomes in gestational diabetes and lesser degrees of glucose intolerance. J Obstet Gynaecol Res 32:107-14

43. Clapp JF, 3rd 2002 Maternal carbohydrate intake and pregnancy outcome. Proc Nutr Soc 61:45-50

44. Resnick O, Miller M, Forbes W, et al. 1979 Developmental protein malnutrition: Influences on the central nervous system of the rat. Neuroscience and biobehavioral reviews 3:233-246

45. Burdge GC, Dunn RL, Wootton SA, Jackson AA 2002 Effect of reduced dietary protein intake on hepatic and plasma essential fatty acid concentrations in the adult female rat: effect of pregnancy and consequences for accumulation of arachidonic and docosahexaenoic acids in fetal liver and brain. Br J Nutr 88:379-87

46. Nielsen GL, Norgard B, Puho E, Rothman KJ, Sorensen HT, Czeizel AE 2005 Risk of specific congenital abnormalities in offspring of women with diabetes. Diabet Med 22:693-6

47. Aslan H, Yanik H, Celikaslan N, Yildirim G, Ceylan Y 2001 Prenatal diagnosis of Caudal Regression Syndrome : a case report. BMC Pregnancy Childbirth 1:8

48. Burns SP, Desai M, Cohen RD, et al. 1997 Gluconeogenesis, glucose handling, and structural changes in livers of the adult offspring of rats partially deprived of protein during pregnancy and lactation. $\mathbf{J}$ Clin Invest 100:1768-74

49. Almeida JR, Mandarim-de-Lacerda CA 2005 Maternal gestational protein-calorie restriction decreases the number of glomeruli and causes glomerular hypertrophy in adult hypertensive rats. Am J Obstet Gynecol 192:945-51

50. Nwagwu MO, Cook A, Langley-Evans SC 2000 Evidence of progressive deterioration of renal function in rats exposed to a maternal low-protein diet in utero. Br J Nutr 83:79-85

51. Rocha SO, Gomes GN, Forti AL, et al. 2005 Long-term effects of maternal diabetes on vascular reactivity and renal function in rat male offspring. Pediatr Res 58:1274-9

52. McMullen S, Gardner DS, Langley-Evans SC 2004 Prenatal programming of angiotensin II type 2 receptor expression in the rat. Br J Nutr 91:133-40

53. Armitage JA, Lakasing L, Taylor PD, et al. 2005 
Developmental programming of aortic and renal structure in offspring of rats fed fat-rich diets in pregnancy. J Physiol 565:171-84

54. Stewart T, Jung FF, Manning J, Vehaskari VM 2005 Kidney immune cell infiltration and oxidative stress contribute to prenatally programmed hypertension. Kidney Int 68:2180-8

55. Anderson RH, Fleming DE, Rhees RW, Kinghorn E 1986 Relationships between sexual activity, plasma testosterone, and the volume of the sexually dimorphic nucleus of the preoptic area in prenatally stressed and non-stressed rats. Brain Res 370:1-10

56. Khan I, Dekou V, Hanson M, Poston L, Taylor P 2004 Predictive adaptive responses to maternal high-fat diet prevent endothelial dysfunction but not hypertension in adult rat offspring. Circulation 110:1097-102

57. Schaefer-Graf UM, Buchanan TA, Xiang A, Songster G, Montoro M, Kjos SL 2000 Patterns of congenital anomalies and relationship to initial maternal fasting glucose levels in pregnancies complicated by type 2 and gestational diabetes. Am J Obstet Gynecol 182:313-20

58. Cheema KK, Dent MR, Saini HK, Aroutiounova N, Tappia PS 2005 Prenatal exposure to maternal undernutrition induces adult cardiac dysfunction. Br J Nutr 93:471-7

59. Fernandez-Twinn DS, Ekizoglou S, Wayman A, Petry CJ, Ozanne SE 2006 Maternal low-protein diet programs cardiac beta-adrenergic response and signaling in 3-moold male offspring. AJP - Regulatory, Integrative and Comparative Physiology 291:R429-436

60. Taylor PD, Khan IY, Lakasing L, et al. 2003 Uterine artery function in pregnant rats fed a diet supplemented with animal lard. Exp Physiol 88:389-98

61. Ghosh P, Bitsanis D, Ghebremeskel K, Crawford MA, Poston L 2001 Abnormal aortic fatty acid composition and small artery function in offspring of rats fed a high fat diet in pregnancy. J Physiol 533:815-22

62. Koukkou E, Ghosh P, Lowy C, Poston L 1998 Offspring of normal and diabetic rats fed saturated fat in pregnancy demonstrate vascular dysfunction. Circulation 98:2899904
63. Hilakivi-Clarke L 1997 Mechanisms by which high maternal fat intake during pregnancy increases breast cancer risk in female rodent offspring. Breast Cancer Res Treat 46:199-214

64. Hilakivi-Clarke L, Clarke R, Onojafe I, Raygada M, Cho E, Lippman M 1997 A maternal diet high in $\mathrm{n}-6$ polyunsaturated fats alters mammary gland development, puberty onset, and breast cancer risk among female rat offspring. Proc Natl Acad Sci U S A 94:9372-7

65. Velie EM, Nechuta S, Osuch JR 2005 Lifetime reproductive and anthropometric risk factors for breast cancer in postmenopausal women. Breast Dis 24:17-35

66. Rose DP 1997 Dietary Fat, Fatty Acids and Breast Cancer. Breast Cancer 4:7-16

67. Olney RS, Mulinare J 2002 Trends in neural tube defect prevalence, folic acid fortification, and vitamin supplement use. Semin Perinatol 26:277-85

68. Varughese GI, Chowdhury SR, Warner DP, Barton DM 2007 Preconception care of women attending adult general diabetes clinics\&mdash;Are we doing enough? Diabetes Research and Clinical Practice 76:142-145

69. Hawthorne G 2006 Metformin use and diabetic pregnancy-has its time come? Diabet Med 23:223-7

70. Waterland RA, Jirtle RL 2003 Transposable elements: targets for early nutritional effects on epigenetic gene regulation. Mol Cell Biol 23:5293-300

71. Langley-Evans SC, Lilley C, McMullen S 2006 Maternal protein restriction and fetal growth: lack of evidence of a role for homocysteine in fetal programming. Br J Nutr 96:578-86

72. Razin A 1998 CpG methylation, chromatin structure and gene silencing-a three-way connection. Embo J 17:49058

73. Rees WD 2002 Manipulating the sulfur amino acid content of the early diet and its implications for longterm health. Proc Nutr Soc 61:71-7

74. Turrell G, Hewitt B, Patterson C, Oldenburg B, Gould T 2002 Socioeconomic differences in food purchasing behaviour and suggested implications for diet-related health promotion. J Hum Nutr Diet 15:355-64 